\title{
Extracorporeal membrane oxygenation to support repeated whole-lung lavage in a patient with pulmonary alveolar proteinosis in life threatening dyspnoe - a case report
}

Martina Krecmerova ${ }^{1,2}$, Frantisek Mosna ${ }^{1,2}$, Vladimír Bicek $^{1,2}$, Frantisek Petrik ${ }^{3}$, Alzbeta Grandcourtova ${ }^{3}$, Marek Lekes ${ }^{4}$ and Tomas Vymazal ${ }^{1,2^{*}}$

\begin{abstract}
Backgroud: Pulmonary alveolar proteinosis is a rare disorder that is characterized by a large accumulation of lipoproteinaceous material within the alveoli. This causes respiratory failure due to a restriction of gas exchange and changes in the ventilation/perfusion ratio. Clinical symptoms are variable and depend on the severity of damage of the lung parenchyma. Treatment method is whole-lung lavage, where the accumulated lipoproteinaceous material is removed using large quantities of saline.

Case presentation: This case report describes a 45 year old patient with advanced pulmonary alveolar proteinosis. Due to the presence of severe global respiratory insufficiency, this patient could not undergo the classic wholelung lavage using a double-lumen tube and selective lung ventilation. The whole-lung lavage was performed with the support of veno-venous extracorporeal membrane oxygenation. A total of 27 I of warm saline was used.

Conclusion: According to the current published literature, whole-lung lavage with extra-corporeal membrane oxygenation support is a very rare treatment method. Even when taking into account all of the risks associated with whole-lung lavage and $v-v$ extracorporeal membrane oxygenation support, we found that this technique is very effective and, without a doubt, it saved the life of our patient.
\end{abstract}

Keywords: Pulmonary alveolar proteinosis (PAP), Whole-lung lavage (WLL), Extracorporeal membrane oxygenation (ECMO), General anesthesia (GA)

\section{Background}

Pulmonary alveolar proteinosis (PAP) is a rare disorder first described by Rosen and colleagues in 1958 [1]. This disease is characterized by an accumulation of phospholipoproteinaceous material inside the alveoli due to a disruption in surfactant homeostasis. The prevalence of PAP is estimated to be around 4 cases per 1 million. Males, smokers and persons between 30 and 50 years are most commonly affected. Symtoms include shortness of breath (dyspnea), cough and, in one

\footnotetext{
* Correspondence: tomas.vymazal@fnmotol.cz

'Department of Anaesthesiology and ICM, 2nd Faculty of Medicine, Charles University in Prague, PragueV Úvalu 84, 150 06Praha 5, Czech Republic ${ }^{2}$ Department of Anaesthesiology and ICM, 2nd Faculty of Medicine, Motol University Hospital, PragueV Úvalu 84, 150 06Praha 5, Czech Republic
} Full list of author information is available at the end of the article third of cases, nail clubbing. Opportunistic bacterial and mycotic infections are common complications. There is a variable interindividual progression of this disease which can range from spontaneous recovery to terminal cardiorespiratory failure. Diagnosis is based on the results from bronchoalveolar lavage (BAL), histology and immunohistochemical tests, on the presence of granulocyte-macrophage colony stimulating factor (GM-CSF) antibodies and computer tomography (CT) or high resolution computer tomography (HRCT) results which typically shows areas of patchy groundglass opacification and interlobular thickening, which together produce the "crazy paving pattern" $[2,3]$.

PAP can occur as an acquired disease (primary or idiopathic PAP) and then is characterized by the production 
of GM-CSF antibodies, therefore is autoimmune in origin. Congenital forms of PAP are less commonly seen and they are caused by a mutated gene responsible for surfactant production or by a mutated receptor for GMCSF. These forms can be treated with medical therapy (GM-CSF substitutes, biological treatment with monoclonal antibodies or plasmapheresis). Secondary forms of PAP are associated with other illnesses, mainly hematooncological diseases, exposure to anorganic materials (eg. silicone), or from side-effect of medication such as immunosuppresive drugs or amiodarone. Rarely, PAP can be a part of the aquired immune deficiency syndrome (AIDS).

The treatment of aquired forms of PAP are mainly bronchoalveolar lavage where the lungs are flushed out with large quantities of saline. This can be performed on individual lung segments, lobes or on the whole lung with possibility for longer pauses between each lavage treatment. The whole-lung lavage (WLL) has been described as the most effective method of treatment $[2,3]$.

\section{Case presentation}

This is a case report of a 45-year old female with a history of work exposure to a dusty environment. She was living on a farm where the hens, rabbits and dogs were present and also had a history of smoking 20 cigarettes a day for 19 years. The patient reported progressive worsening of the shortness of breath on exertion for the last year. A diagnosis of PAP was performed based on the HRCT and BAL results. One-sided lung lavage was repeatedly performed with the final procedure being complicated by acute respiratory failure and the need for mechanical ventilation. The therapeutic effect of the lavage treatments was short-lived and was followed by progression of the disease. Oxygen saturation on room air at rest $(\mathrm{SpO} 2)$ was measured as low as $80 \%$. The patient was therefore dependent on a long-term home oxygen therapy. One year following the diagnose of PAP, $\mathrm{SpO} 2$ at rest on room air dropped to $72 \%$. The patient's health status began to deteriorate, withan insufficiency of the right heart developing and a Mycobacterium intracellular lung infection was diagnosed and was subsequently repeatedly treated with a combination of antibodies. High resolution computed tomography results showed a severe 'crazy paving' pattern bilaterally. Arterial blood gas on home oxygen therapy with $\mathrm{O} 2$ at $6 \mathrm{~L} / \mathrm{min}$ showed $\mathrm{pO} 26.36 \mathrm{kPa}$ and $\mathrm{pCO} 23.6 \mathrm{kPa}$. Due to rapid disease progression and the presence of severe respiratory insufficiency, the patient was indicated for the bilateral lung lavage and the procedure was performed using veno-venous ECMO support. The protocol recommended by the American College of Chest Physicians from 2009 was followed during the performance of this treatment [4].
Upon admission to the operating theatre, non-invasive monitoring was commenced (electrocardiograph - ECG, non-invasive blood pressure measurement - NIBP, pulse oximetry). The initial values were as follows - sinus rhythm 90/min, NIBP $160 / 90 \mathrm{mmHg}, \mathrm{SpO} 2$ ( on the room air ) was $80 \%$. An $18 \mathrm{G}$ peripheral venous cannula was placed to the right cubital vein. Induction to general anesthesia was commenced with remifentanil at $0.25 \mathrm{ug} /$ $\mathrm{kg} / \mathrm{min}, 180 \mathrm{mg}$ of propofol and $70 \mathrm{mg}$ of rocuronium. Tracheal intubation was performed with a $37 \mathrm{Ch}$ left-sided double-lumen tube without a carinal hook (Robertshaw) and its position was confirmed with a bronchoscope. A urinary catheter was inserted. The patient was ventilated using volume-controlled ventilation (VCV) with a tidal volume of $480 \mathrm{~mL}$ during bilateral lung ventilation, a respiratory rate of 10 breaths $/ \mathrm{min}$, an inspiration:expiration ratio of $1: 2$, positive-end expiratory pressure (PEEP) of $5 \mathrm{~cm} \mathrm{H} 2 \mathrm{O}$ and the initial $\mathrm{FiO} 2$ was 1.0. Ventilation was adjusted based on the $\mathrm{SpO} 2$ and ETCO2 values until the introduction of the $\mathrm{v}-\mathrm{v}$ ECMO. Anesthesia was maintained intravenously (TIVA) with propofol at a dosage of $0.7 \mathrm{mcg} / \mathrm{Kg} / \mathrm{min}$ and analgesia with remifentanil at a dosage of $0.16 \mathrm{mcg} /$ $\mathrm{kg} / \mathrm{min}$. Based on the recommendation of the Local Hospital Drug Commitee, the procedure was performed with antibiotic prophylaxis using $2 \mathrm{~g}$ of cefotaxim 6 hourly.

After examination of both internal jugular veins and femoral veins, a $8.5 \mathrm{Fr}$ x $20 \mathrm{~cm}$ central venous catheter was insered into the left internal jugular vein. Additionally, a $8.5 \mathrm{Fr} \times 10 \mathrm{~cm}$ sheath was placed into the left subclavian vein to allow for potential invasive monitoring using a pulmonary catheter or in the instance that high-volume fluid therapy would be necessary. Arterial cannulation was performed on the left radial artery to ensure direct blood pressure monitoring.

Selective ventilation of the right or left lung was not possible due to the production of a right-left shunt which would lead to the severe derangement of oxygenation and highly increase the accumulation of $\mathrm{CO} 2$ in the body.

Using transesophaegeal echocardiography (TEE), the kinetics of the left and right heart were found to be normal without any valve pathology or pericardial separation. A bolus of heparin (5000 I.U.) was administered prior to cannulation for the $\mathrm{v}-\mathrm{v}$ ECMO. The infusion cannula was placed in the right internal jugular vein while the drainage cannula was placed in the right femoral vein. The position of the both infusion cannulas was confirmed using TEE. The flow through ECMO was set at $4837 \mathrm{~mL} / \mathrm{min}$ and was determined after calculating the patient's body surface area which was $1.79 \mathrm{~m} 2$. After reaching a flow of $4500 \mathrm{~mL} / \mathrm{min}$ on the ECMO with a $\mathrm{FiO} 2$ of 0.8 , then the parametres of mechanical 
ventilation were adjusted accordingly (tidal volume - Vt 300-350 ml, respiratory frequency - RF 10 per minute, PEEP $5 \mathrm{cmH} 2 \mathrm{O}, \mathrm{FiO} 2 \mathrm{0}, 4)$. Body core temperature was measured in the esophagus. The activated clotting time (ACT) was measured at precise intervals and heparin boluses were given every 160-200 s.

After fixation of the ECMO cannulae, the patient was positioned on her right side. The position of the DLT was checked with a bronchoscope. Prior to insertion, both cuffs were tested under water for any leakage. The operating table was placed in anti-Trendelenburg ("head up") position. Subsequently, the first $1000 \mathrm{~mL}$ of warmed $\left(37^{\circ} \mathrm{C}\right) \mathrm{sa}-$ line was introduced into the left lung, after which followed a 4 min long manual physiotherapeutic massage of the chest wall - using percussional postural massage and vibrational techniques with the goal of freeing the maximal amount of accumulated material. Afterwards, the fluid was released with the help of gravity by placing the patient in the Trendelenberg position ("head down"). This procedure was repeated several times. At first, the collected fluid was yellowish-white and cloudy with floccules that sedimented and were collected. Progressively, the fluid became more and more clear (Fig. 1).

After completing the lavage of the left lung, the patient was positioned on her left side and the same procedure was performed on the right lung. Over $225 \mathrm{~min}$, the left lung was rinsed with $12,000 \mathrm{~mL}$ of warm saline and $11,680 \mathrm{~mL}$ of the fluid was collected $(320 \mathrm{~mL}$ were absorbed) and over the course of $150 \mathrm{~min}$, the right lung was rinsed with $15,000 \mathrm{~mL}$ of warm saline and 14,530 mL were collected ( $470 \mathrm{~mL}$ were absorbed). During the entire procedure, several incidents of isolated hemodynamically insignificant supraventricular and polytopic ventricular ectopics were registered but did not require any intervention. Normothermia was maintained for the duration of the procedure. Electrolyte levels were monitored

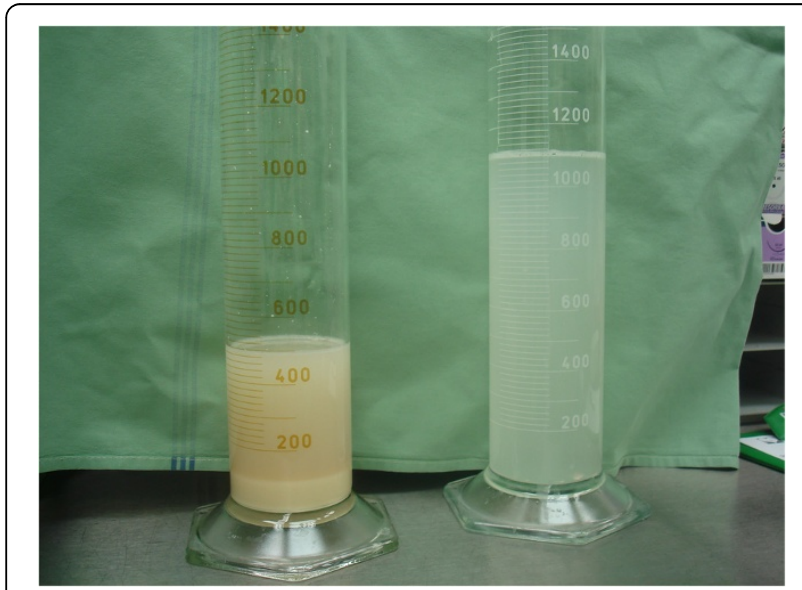

Fig. 1 The character of the first (on the left) and the last portions of fluid used for the lung lavage throughout the procedure and the levels of potassium and magnesium had to be corrected. Diuresis was supported using furosemide at a dosage of $15 \mathrm{mg} / \mathrm{h}$. In order to ensure proper perfusion, mean arterial pressure (MAP) was maintained at $75 \mathrm{mmHg}$ by continuous administration of norepinephrine at a dosage of $0.10-0.15 \mathrm{ug} / \mathrm{kg} / \mathrm{min}$.

Oxygenation parameters during the procedure which lasted $9 \mathrm{~h}$ are summarized at the Table 1.

The v-v ECMO flow was held at maximum values for the entire duration of the procedure, in order to decrease the amount of desaturated blood flow through the lung undergoing lavage. The $\mathrm{FiO} 2$ values on the ECMO were determined according to the patient $\mathrm{paO} 2$ and varied between 0.6 and 0.8 for the duration of the procedure. It is clear from the initial oxygen values that without the use of the $\mathrm{v}-\mathrm{v}$ ECMO, the bilateral lung lavage would have caused life threatening hypoxia. The patient's life would also have been endangered by significant hypercarbia leading to respiratory acidosis. The physiological value of pCO2 was adjusted by changing of gas flow on the ECMO.

After completion of the bilateral lung lavage, the patient was placed on her back and re-intubated with an ordinary endotracheal tube size 7.5. A small amount of remaining fluid was removed from the lungs bronchoscopically. The sedated and hemodynamically stable patient was then moved to the intensive care unit with continued support of the v-v ECMO. In the first few hours post-op, there was a progressive worsening of oxygenation and a left-sided pneumothorax was diagnosed. After the prompt insertion of a chest drain, this was corrected. Due to an insufficient diuresis and risk of hypervolemia, continuous renal replacement therapy (CRRT) was initiated. Within three days, the CRRT and $\mathrm{v}-\mathrm{v}$ ECMO were discontinued and ventilatory weaning was started On the 9th day, the patient was extubated, but due to poor oxygenation and a hypoxemic index of 200, she was soon placed on non-invasive ventilation. On the 11th day the patient was transferred from the ICU to the Respiratory Care Department for further treatment.

Table 1 Oxygenation parameters during the procedure

\begin{tabular}{|c|c|c|c|}
\hline Initial value & $\mathrm{FiO} 20.21$ & $\mathrm{paO} 26.36 \mathrm{kPa}$ & $\begin{array}{l}\mathrm{SaO} 285 \%, \\
\mathrm{SpO} 280 \%\end{array}$ \\
\hline After induction & FiO2 1.0 & & SpO2 93 \% \\
\hline v-v ECMO start & $\mathrm{FiO} 20.8$ & $\mathrm{paO} 239.78 \mathrm{kPa}$ & $\mathrm{SaO} 2100 \%$ \\
\hline $\begin{array}{l}\text { After } 90 \text { min of left } \\
\text { lung lavage, v-v ECMO }\end{array}$ & $\mathrm{FiO} 20.6$ & $\mathrm{paO} 216.16 \mathrm{kPa}$ & $\mathrm{SaO} 298 \%$ \\
\hline $\begin{array}{l}225 \mathrm{~min} \text { - end time } \\
\text { of left lung lavage, } \\
\mathrm{v}-\mathrm{v} \mathrm{ECMO}\end{array}$ & $\mathrm{FiO} 20.8$ & $\mathrm{paO} 211.59 \mathrm{kPa}$ & $\mathrm{SaO} 295,5 \%$ \\
\hline $\begin{array}{l}\text { Next } 150 \mathrm{~min}-\text { end } \\
\text { time of right lung } \\
\text { lavage, } v-\mathrm{v} \text { ECMO }\end{array}$ & FiO2 0.8 & $\mathrm{paO} 2$ 13,62 kPa & $\mathrm{SaO} 297,7 \%$ \\
\hline
\end{tabular}




\section{Conclusion}

Pulmonary alveolar proteinosis caused life-threatening respiratory failure in our patient with $\mathrm{SaO} 2$ levels below $75 \%$. The only possibility for treatment was bilateral bronchoalveolar lavage which would rinse the accumulated lipoproteinaceous material out of the lungs using warm saline. Abdelmalak et al. published [2] their experience with high volume wash (up to $50 \mathrm{~L}$ in very severe cases) without the need for ECMO and discussed others'approach utilizing hyperbaric oxygen. Noirez et al. presented [3] a 3-step strategy that was used in a patient with PAP-associated refractory hypoxemia and that combined venovenous extracorporeal membrane oxygenation, double-lumen orotracheal intubation, and bilateral multisegmental sequential lavage. In compliance with current literature $[2,3]$ the oxygenation and ventilation was assured by v-v ECMO and double-lumen orotracheal intubation during the procedure. The oxygenation improved dramatically on $\mathrm{v}-\mathrm{v}$ ECMO in our patient. In the literature, a few similar cases have been published [5, 6]. The first WLL was performed by Ramirez in 1963 [7]. WLL can be performed with or without ECMO [2, 3, 8]. The WLL procedure could be accompanied by derangements of the acid-base and electrolyte balance and hypervolemia $[2,8]$. There is no published information about quantity of absorbed chloride in current literature. In our case, $790 \mathrm{~mL}$ of saline was absorbed by the lungs. The plasmatic level of the chloride was checked repeatedly and remained within the physiological range. Since severe generalized oedema of soft tissues was observed together with a change in diuresis, an undefined quantity of chloride is supposed to have been absorbed into the third space. The type of crystalloid to be used in this procedure has not yet been standardized. Derangement of the electrolyte homeostasis causing cardiac arrhythmias could be avoided using Ringer's solution [5]. The WLL may also be complicated by pneumotorax [9]. Standardized protocols for WLL have not yet been established. Other methods of treatment are GM-CSF substitutes applied subcutaneously or inhalationally, biological treatment with monoclonal antibodies, plasmapheresis, hyperbaric oxygenoterapy and, in severe cases, even lung transplantation $[2,3,10]$. In our case, we decided for WLL with v-v ECMO support due to the severity of the patient's clinical status and with full knowledge of all associated risks. We found this technique to be very effective and, without a doubt, it saved the life of our patient.

Bilateral lung lavage with the support of VV-ECMO is an effective, and often the only feasible, therapeutic method in patients with pulmonary alveolar proteinosis. Quality multidisiplinary teamwork is extremely important.

\section{Ethics approval}

The agreement of the Ethics Committee of University Hospital Motol with this case report's publication was voiced.

\section{Statement to confirm}

Written informed consent was obtained from the patient for publication of this case report and any accompanying images. A copy of the written consent is available for review by the Editor of this journal.

\section{Abbreviations \\ AIDS: acquired immunodeficience virus; BAL: bronchoalveolar lavage; CT: computer tomography; ECMO: extracorporeal membrane oxygenation; GM-CSF: granulocyte-macrophage colony stimulating factor; HRCT: high resolution computer tomography; PAP: pulmonary alveolar proteinosis; PEEP: positive end-expiratory pressure; TIVA: total intravenous anesthesia; VCV: volume-controled ventilation; $v$ - $v$ ECMO: veno-venous extracorporeal membrane oxygenation; WLL: whole-lung lavage.}

\section{Competing interests}

All authors declare no financial, personal, or relationships with other people or organizations within 3 years of beginning the work submitted that could inappropriately influence the work submitted.

Copyright By submitting a manuscript, the authors agree that the copyright of their article is transferred to the publishers if and when the article is accepted for publication.

\section{Authors' contributions}

MK has made substantial contributions to conception and design, acquisition, analysing and interpretation of data, has been involved in drafting the manuscript or revising it critically for important intellectual content. She agreed to be accountable for all aspects of the work in ensuring that questions related to the accuracy or integrity of any part of the work are appropriately investigated and resolved. FM has made substantial contributions to conception and design, acquisition, analysing and interpretation of data. VB has made substantial contributions to conception and design, acquisition, analysing and interpretation of data. TV has made substantial contributions to conception and design, analysis and interpretation of data, has been involved in drafting the manuscript and revising it critically for important intellectual content, has given final approval of the version to be published. He agreed to be accountable for all aspects of the work in ensuring that questions related to the accuracy or integrity of any part of the work are appropriately investigated and resolved. FP has made contributions to acquisition and interpretation of data and has revised critically for important intellectual content. AG has made contributions to acquisition and interpretation of data and has revised critically for important intellectual content. She has been involved in drafting the manuskript. $\mathrm{ML}$ has made contributions to acquisition and interpretation of data and has revised critically for important intellectual content. All authors read and approved the final manuscript.

\section{Author details}

${ }^{1}$ Department of Anaesthesiology and ICM, 2nd Faculty of Medicine, Charles University in Prague, PragueV Úvalu 84, 150 06Praha 5, Czech Republic.

${ }^{2}$ Department of Anaesthesiology and ICM, 2nd Faculty of Medicine, Motol University Hospital, PragueV Úvalu 84, 150 06Praha 5, Czech Republic.

${ }^{3}$ Pneumology Department, 2nd Faculty of Medicine, Charles University in Prague, PragueV Úvalu 84, 150 06Praha 5, Czech Republic. ${ }^{4}$ Department of Rehabilitation and Sports Medicine, 2nd Faculty of Medicine, Charles University in Prague, PragueV Úvalu 84, 150 06Praha 5, Czech Republic.

Received: 8 April 2015 Accepted: 19 November 2015

Published online: 30 November 2015 


\section{References}

1. Rosen SH, Castleman B, Liebow AA. Pulmonary alveolar proteinosis. N Engl J Med. 1958;258(23):1123-42

2. Abdelmalak BB, Khanna AK, Culver DA, Popovich MJ. Therapeutic whole-lung lavage for pulmonary alveolar proteinosis: a procedural update. J Bronchol Interv Pulmonol. 2015;22(3):251-8. doi:10.1097/LBR. 0000000000000180 .

3. Noirez L, Koutsokera A, Pantet O, Duss FR, Eggimann P, Tozzi P, et al: A 3-step therapeutic strategy for severe alveolar proteinosis. Ann Thorac Surg. 2015;99(4):1456-8. doi:10.1016/j.athoracsur.2014.12.080.

4. Michaud G, Reddy C, Ernst A. Whole-lung lavage for pulmonary alveolar proteinosis. Chest. 2009;136(6):1678-81.

5. Sivitanidis $\mathrm{E}$, Tosson $\mathrm{R}$, Wiebalck A, Laczkovics A. Combination of extracorporeal membrane oxygenation (ECMO) and pulmonary lavage in a patient with pulmonary alveolar proteinosis. Eur J Cardio-Thorac Surg. 1999;15:370-2

6. Cohen ES, Elpern E, Silver MR. Pulmonary alveolar proteinosis causing severe hypoxemic respiratory failure treated with sequential whole-lung lavage utilizing venovenous extracorporeal membrane oxygenation.

Chest. 2001;120:1024-6.

7. Ramirez J, Schultz RB, Dutton RE. Pulmonary alveolar proteinosis: a New technique and rationale for treatment. Arch Intern Med. 1963;112:419-31.

8. Vymazal T, Krecmerova M. Respiratory strategies and airway management in patients with pulmonary alveolar proteinosis: a review. BioMed Res Int 2015. 2015:Article ID 639543:5. doi:10.1155/2015/639543.

9. Centella T, Oliva E, Andrade IG, Epeldegui A. The use of a membrane oxygenator with extracorporeal circulation in bronchoalveolar lavage for alveolar proteinosis. Interact CardioVasc Thorac Surg. 2005;4:447-9.

10. Borie R, Danel C, Debray M-P, Taille C, Dombret M-C, Aubier M, et al. Pulmonary alveolar proteinosis. Eur Respir Rev. 2011;20(120):98-107.

\section{Submit your next manuscript to BioMed Central and we will help you at every step:}

- We accept pre-submission inquiries

- Our selector tool helps you to find the most relevant journal

- We provide round the clock customer support

- Convenient online submission

- Thorough peer review

- Inclusion in PubMed and all major indexing services

- Maximum visibility for your research 